\title{
Colonic Obstruction, CTCAE
}

National Cancer Institute

\section{Source}

National Cancer Institute. Colonic Obstruction, CT CAE. NCI Thesaurus. Code C143375.

A disorder characterized by blockage of the normal flow of the intestinal contents in the colon. 